\title{
RETROSPECTIVA HISTÓRICA DA PSICOPEDAGOGIA NO CONTEXTO BRASILEIRO: GÊNESE, DOCUMENTAÇÃO E LEGALIZAÇÃO
}

\author{
RETROSPECTIVA HISTÓRICA DE LA PSICOPEDAGOGÍA EN EL CONTEXTO \\ BRASILEÑO: GÉNESIS, DOCUMENTACIÓN Y LEGALIZACIÓN
}

\author{
HISTORICAL RETROSPECTIVE OF PSYCHOPEDAGOGY IN THE BRAZILIAN \\ CONTEXT: GENESIS, DOCUMENTATION AND LEGALIZATION
}

RESUMO: O presente artigo traz um recorte do aporte teórico da tese de doutorado intitulada "O psicopedagogo na rede pública municipal em sete estados brasileiros: cenários e desafios", abrangendo a trajetória histórica da Psicopedagogia no contexto brasileiro desde 1970 até 2020. A metodologia adotada é de cunho teórico-bibliográfico, a qual objetivou a recuperação da gênese da Psicopedagogia, abrangendo inclusive dados da criação dos documentos e órgãos representativos da referida área. Assim, constatou-se a importância da Associação Brasileira de Psicopedagogia (ABPp), dos congressos, eventos, debates e encontros realizados a nível regional, estadual e nacional, os quais contribuíram para discussões e reflexões sobre a Psicopedagogia no Brasil, a formação e atuação do psicopedagogo, a identidade profissional e a regulamentação da profissão.

PALAVRAS-CHAVE: Psicopedagogia. Gênese. Contexto brasileiro.

RESUMEN: Este artículo trae una contribución teórica de la tesis doctoral titulada "El psicopedagogo en la red pública municipal en siete estados brasileños: escenarios y desafios", abarcando la trayectoria histórica de la psicopedagogía en el contexto brasileño desde 1970 hasta 2020. La metodología adoptada es de carácter teórico y bibliográfico, que tuvo como objetivo recuperar la génesis de la Psicopedagogía, incluyendo datos de la creación de documentos y órganos representativos del área. Así, se verificó la importancia de la Asociación Brasileña de Psicopedagogía (ABPp), de los congresos, eventos, debates y encuentros realizados a nivel regional, estatal y nacional, que contribuyeron a las discusiones y reflexiones sobre la Psicopedagogía en Brasil, la formación y actuación del psicopedagogo, la identidad profesional y la regulación de la profesión.

\section{PALABRAS CLAVE: Psicopedagogía. Génesis. Contexto brasileño.}

\footnotetext{
${ }^{1}$ Universidade Estadual do Paraná (UNESPAR), União da Vitória - PR - Brasil. Docente colaboradora do Colegiado de Pedagogia. Membro do Grupo de Pesquisa em Educação: Aprendizagem e Conhecimento na Prática Docente (PUCPR). Membro do Grupo de Estudos e Pesquisa em Educação: teoria e prática (GEPE). Membro do Grupo de Estudos e Pesquisas em Práxis Educativa (GEPPRAX). Doutorado em Educação (PUCPR). ORCID: https://orcid.org/0000-0002-9741-2823. E-mail: carolineblaszko2020@gmail.com

${ }^{2}$ Pontifícia Universidade Católica do Paraná (PUCPR), Curitiba - PR - Brasil. Professora Titular do Curso de Pedagogia, Licenciaturas, Programa Stricto Sensu em Educação e Coordenadora do Curso de Psicopedagogia. Coordenadora do Grupo de Pesquisa Aprendizagem e Conhecimento na Prática Docente. Conselheira Nata da Associação Brasileira de Psicopedagogia - seção Paraná. Doutora em Educação (UCM) - Espanha. ORCID: https://orcid.org/0000-0003-4557-0130.E-mail: eveliseportilho@gmail.com
} 
ABSTRACT: This article presents a theoretical contribution of the doctoral thesis entitled "The psychopedagogue in the municipal public network in seven Brazilian states: scenarios and challenges", covering the historical trajectory of psychopedagogy in the Brazilian context from 1970 to 2020. The methodology adopted is of a theoretical and bibliographical nature, which aimed at recovering the genesis of Psychopedagogy, including data on the creation of documents and representative bodies of the area. Thus, the importance of the Brazilian Association of Psychopedagogy (ABPp) was verified, as well as the congresses, events, debates, and meetings held at regional, state, and national levels, which contributed to discussions and reflections on Psychopedagogy in Brazil, the formation and performance of the psychopedagogue, the professional identity and the regulation of the profession.

KEYWORDS: Psychopedagogy. Genesis. Brazilian context.

\section{Introdução}

Neste estudo buscamos trazer aspectos da trajetória histórica da Psicopedagogia no contexto brasileiro desde 1970 até 2020, abrangendo dados sobre o surgimento da Psicopedagogia, os principais congressos, eventos, estudos, pesquisas, documentos e a criação de órgãos representativos da Psicopedagogia como a ABPp, Seções e Núcleos. Neste sentido, evidencia-se também que a construção de um corpo teórico próprio vem fortalecendo e consolidando a história da Psicopedagogia no Brasil.

A metodologia adotada neste artigo é de cunho teórico-bibliográfico, que segundo Gil (2002, p.44), pode ser “desenvolvida com base em material já elaborado, constituído principalmente de livros e artigos científicos" e a partir de fontes bibliográficas.

Os dados advindos da pesquisa teórico-bibliográfica foram organizados em ordem cronológica, sendo apresentados em dois momentos: o primeiro traz um panorama histórico da Psicopedagogia no Brasil desde 1970 até 2020, e o segundo apresenta aspectos com relação à regulamentação e à criação de documentos com a finalidade de normatizar e nortear a atuação do psicopedagogo no Brasil.

\section{Panorama histórico da Psicopedagogia no Brasil}

Primeiramente é necessário compreender o conceito de Psicopedagogia, que segundo a ABPp (2019, p.1) é definida como "um campo de conhecimento e ação interdisciplinar em Educação e Saúde com diferentes sujeitos e sistemas, quer sejam pessoas, grupos, instituições e comunidades". Ainda segundo o documento, a Psicopedagogia tem como objeto de estudo a 
aprendizagem humana, considerando os sujeitos e sistemas, a família, a escola, a sociedade, o contexto social, histórico e cultural.

Conforme as Diretrizes da Formação do Psicopedagogo no Brasil, a Psicopedagogia é "uma área de conhecimento, atuação e pesquisa, que lida com o processo de aprendizagem humana, visando o apoio aos indivíduos e aos grupos envolvidos neste processo, na perspectiva da diversidade e da inclusão" (ABPp, 2013a, p. 1).

Destaca-se que o conceito de Psicopedagogia apresentado é resultado da evolução dos estudos e discussões que ocorreram ao logo da trajetória histórica, visto que, inicialmente, a Psicopedagogia focava o olhar nas dificuldades de aprendizagem e no fracasso escolar e, atualmente, tem como objeto o estudo do processo de aprendizagem humana.

A Psicopedagogia surgiu no Brasil na década de 1970 e tem sua trajetória histórica influenciada por autores estrangeiros, como Sara Paín, Jorge Visca, Alicia Fernández, Ana Maria Rodriguez Muñiz, Bernardo Quirós, Jacob Feldman, e autores brasileiros, tais como: Lino de Macedo, Neide Aquino Noffs, Maria Cecilia Almeida e Silva, Nádia Bossa, Elcie Masini, Maria Lúcia Lemme Weiss, Beatriz Judite Scoz, Eloisa Quadros Fagali, Edith Regina Rubinstein, Maria Aparecida Neves, Leda M. Codeço Barone, Maria Célia R. Malta Campos, Maria Cristina Natel, Laura Monte Serrat Barbosa, Evelise Maria Labatut Portilho, Isabel Cristina Hierro Parolin, Simone Carlberg, Neusa Hickele, entre outros.

No Brasil, a Psicopedagogia tem sua gênese demarcada por um movimento que promoveu aos profissionais da educação formações, supervisões, assessoramentos, bem como o contato com diferentes posições teóricas sobre o processo de ensinar e aprender.

Outrossim, a gênese da Psicopedagogia vincula-se à necessidade de atender seres humanos que apresentam dificuldades de aprendizagem. Nesse sentido, Almeida e Silva (2018) afirmam que, no início, o objeto de estudo da Psicopedagogia eram os sintomas das dificuldades de aprendizagem, e os objetivos consistiam em remediá-los

$\mathrm{Na}$ década de 1970, os problemas de aprendizagem eram associados à disfunção neurológica, chamada também de Disfunção Cerebral Mínima (DCM). Nesse caso, prevalecia a explicação organicista dos problemas de aprendizagem, a atitude medicalizadora e a visão patológica que, segundo Barbosa (2006, p. 52), "passou a ter a conotação de cura e não de superação processual das dificuldades de aprendizagem". Assim, nessa década, as pessoas que apresentavam dificuldades de aprendizagem eram encaminhadas para atendimento com especialistas da área médica, os quais emitiam um diagnóstico justificando as referidas dificuldades. 
Salienta-se que ao final da década de 1970, Jorge Visca traz para a Psicopedagogia o fundamento teórico que foi sistematizado por Pichon-Riviére, denominado Epistemologia Convergente e "vem ao Rio de Janeiro [Jorge Visca], convidado pela Escola Movimento (RJ), ministrar os primeiros cursos livres sobre Psicopedagogia em bases construtivistas, interacionista e estruturalista" (RODRIGUES; NOFFS; FABRÍCIO, 1997, p. 6).

Neste sentido, Barbosa (2012, p. 13) complementa que na década de 1970 "a Epistemologia Convergente como fundamento de uma proposta psicopedagógica chegou no Brasil”, a qual foi amplamente divulgada no Rio de Janeiro, Curitiba, Campinas, Salvador, São Paulo e, posteriormente, estendeu-se para outras regiões do país por meio de seus seguidores.

Segundo a teoria da Epistemologia Convergente, a aprendizagem é "concebida como um processo, no qual o aprendiz possui uma participação intensa sobre seu próprio aprendizado, articulando cognição e afeto e garantindo que o conhecimento seja desejado e, por isso, aprendido" (BARBOSA, 2012, p. 13).

Surgiram os primeiros cursos de especialização no campo da Psicopedagogia no Brasil a partir da década de 1970, com o objetivo de contribuir para a formação de profissionais que atendiam as pessoas com problemas de aprendizagem. Tem-se o registro que os primeiros cursos com enfoque psicopedagógico foram oferecidos na Pontifícia Universidade Católica de

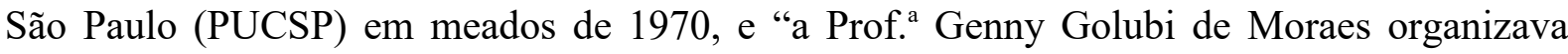
cursos voltados para as dificuldades escolares e coordenava um serviço de atendimento clínico para crianças da rede pública na Clínica da PUCSP” (RUBINSTEIN; CASTANHO; NOFFS, 2004, p. 229).

Entre os anos de 1970 e 1972, foi oferecido em Porto Alegre, no estado do Rio Grande do Sul, o curso de formação de psicopedagogos na Clínica Médica Psicopedagógica que, depois, nos anos de 1974 e 1975, foi adaptado e levado à Universidade Federal do Rio Grande do Sul, transformando-se em curso de especialização de Psicopedagogia.

Criou-se em São Paulo no ano de 1979 o primeiro "curso regular de Psicopedagogia, no Instituto Sedes Sapientiae, iniciativa de Maria Alice Vassimon, pedagoga e psicodramatista, e de madre Cristina Sodré Dória, diretora do Instituto" (RUBINSTEIN; CASTANHO; NOFFS, 2004, p. 229).

Em seguida surgiram os cursos de especialização lato sensu em Psicopedagogia no estado de São Paulo a partir da década de 1980, que depois se estenderam para outras instituições e regiões do Brasil. Nessa década, segundo Rubinstein, Castanho e Noffs (2004, p. 230), a formação de profissionais em Psicopedagogia em diferentes capitais brasileiras 
"tiveram [teve] a colaboração importante de psicopedagogos [...] que mostraram a possibilidade de compreender o aluno que fracassa a partir de uma visão integrada".

Outro marco importante foi a fundação da Associação Paulista de Psicopedagogos em 12 de novembro de 1980, que, posteriormente, transformou-se em ABPp (BARBOSA, 1994). Evidenciamos que a ABPp é "uma associação de direito privado, de âmbito nacional, não possui fins lucrativos e econômicos, possui caráter técnico, científico e social, com foco preponderante nas atividades de Psicopedagogia" (ABPp, 2013b, p. 1).

A criação da ABPp representa um marco para a classe dos psicopedagogos, consolidando-se como um órgão de referência nacional, comprometido com o aprimoramento técnico-científico, tendo por função agregar os profissionais do território brasileiro, engajando-os em debates, reuniões, conferências, cursos, seminários, congressos e eventos de âmbitos regional, estadual, nacional ou internacional.

Também a ABPp, como "órgão de classe desde a década de 80, quando foi constituída, mostra-se preocupada com várias questões: regulamentação da profissão, ética e formação, entre outras prioridades" (RUBINSTEIN; CASTANHO; NOFFS, 2004, p. 233).

Em 1982 ocorreu a elaboração do primeiro Boletim na área da Psicopedagogia, que deu origem, em 1991, à revista Psicopedagogia. Esta se mantém até hoje com publicações contínuas, conservando a qualidade, promovendo discussões, debates e o fortalecimento de um corpo teórico que possibilita aos psicopedagogos novas reflexões e o aperfeiçoamento de sua prática. Cabe evidenciar que o Boletim e a revista Psicopedagogia são importantes para a constituição da identidade da Psicopedagogia no Brasil, pois por muitos anos consecutivos constituíram a única fonte de divulgação de conhecimentos da referida área (BAPTISTA, 1996).

Para atender as crianças que apresentavam dificuldades de aprendizagem, foi criado, em 1983, o Núcleo de Orientação e Aconselhamento Psicopedagógico (NOAP) do Departamento de Educação da Pontifícia Universidade Católica do Rio de Janeiro (PUCRIO). Segundo Teixeira e Freitas (1993), o trabalho desenvolvido pelo referido núcleo procurou integrar a universidade, comunidade e escola básica; sendo assim, foi oferecida às escolas a possibilidade de a universidade desenvolver ações no próprio cenário do contexto escolar.

Em seguida, no ano de 1984, foi realizado o $1^{\circ}$ Encontro de Psicopedagogos em São Paulo, abrangendo a temática "Experiências e perspectivas do trabalho psicopedagógico na realidade brasileira", com o temário "A Psicopedagogia - visão preventiva e terapêutica no processo de aprendizagem da criança, do adolescente e do adulto na educação formal e 
informal e em diferentes instituições". Tal encontro teve como objetivos: reunir psicopedagogos, pesquisadores e profissionais das diversas áreas - educadores, psicólogos, neurologistas, psiquiatras, fonoaudiólogos, terapeutas educacionais e outros que contribuem para o conhecimento teórico e prático da Psicopedagogia; discutir tendências teóricas e práticas nas abordagens preventivas e terapêuticas da Psicopedagogia; situar de forma abrangente o papel profissional e a identidade do psicopedagogo em nosso meio; propor a criação da Associação Brasileira da Psicopedagogia e a formação de associações estaduais (BARBOSA, 1994).

Nesse primeiro $1^{\circ}$ Encontro de Psicopedagogos é que foi proposta a transformação da Associação Estadual de Psicopedagogos de São Paulo em ABPp, que incorpora, em sua história, a data da fundação da Associação Paulista de Psicopedagogos (BARBOSA, 1994). Em várias regiões do Brasil, nesse mesmo ano, ocorreram movimentos e debates com o objetivo de definir o perfil do profissional psicopedagogo.

Iniciou-se em nível particular o primeiro curso formal de Psicopedagogia Clínica no Centro de Estudos Psicopedagógicos do Rio de Janeiro na década de 1980, o qual seguia o modelo realizado pelo Centro de Estudos de Buenos Aires, dirigido por Jorge Visca. Nesse período, a Universidade Estadual do Rio de Janeiro (UERJ) criou o Serviço de Psicopedagogia, que objetivava atender a comunidade local.

Seguindo um percurso histórico, em 1986 foi realizado o II Encontro de Psicopedagogia e, no mesmo ano, ocorreu o III Encontro e I Congresso Nacional de Psicopedagogia, como esfera aglutinadora e organizadora dos debates e normatizações das diretrizes para o campo da Psicopedagogia. Os referidos eventos possibilitaram espaço para maior número de participantes com conhecimentos diversificados, com o intuito de aproximar os profissionais e construir uma visão abrangente sobre a aprendizagem.

Entre os anos de 1986 e 1987, no Rio de Janeiro, ocorreram encontros entre profissionais da área da Psicopedagogia e representantes de instituições universitárias, que objetivaram a criação da Associação Brasileira de Psicopedagogia - Seção Rio de Janeiro (ABPp-RJ), a qual foi criada em 1987. A referida Associação "foi a segunda criada no Brasil e, a partir da sua fundação, vem realizando eventos científicos periódicos com objetivo primeiro de atender às necessidades dos profissionais envolvidos com a aprendizagem" (ZENICOLA; CASTRO, 2007, p. 152).

A partir da década de 1990, observa-se também que houve uma ampliação da práxis psicopedagógica, a qual passou a entender o ser humano como sujeito ativo de sua aprendizagem e vinculado ao outro que ensina (BERLIM; PORTELLA, 2007). 
Em seguida, foi criado em 1990 o primeiro curso de especialização em Psicopedagogia na Pontifícia Universidade Católica do Paraná, sendo que a seleção dos candidatos foi realizada mediante análise do curriculum vitae, exigindo experiência profissional de no mínimo dois anos e a graduação no nível de $3^{\circ}$ grau (PORTILHO, 1992). Conforme a autora, o curso de Psicopedagogia tem como objetivo integrar as várias áreas do conhecimento para estudar de forma aprofundada a aprendizagem como processo dinâmico e evolutivo.

Também em Belo Horizonte, na década de 1990, foi criado o primeiro curso de Psicopedagogia em nível de pós-graduação lato sensu, desenvolvido pelo Centro de Extensão e Pesquisa do Instituto de Educação do estado de Minas Gerais (RUBINSTEIN; CASTANHO; NOFFS, 2004). A partir dessa década, no Brasil, consta-se que os cursos de Especialização em Psicopedagogia aumentaram consideravelmente, sendo oferecidos por várias universidades brasileiras.

Em 1990 foi fundada a Associação Brasileira de Psicopedagogia - Seção Goiás (ABPp-GO), que desenvolveu várias ações, como a realização de Cursos de Formação para o psicopedagogo, que possibilitou aos profissionais da área da capital e do interior a chance de aprimorar seus conhecimentos e suas práticas psicopedagógicas (ABPp-GO, 2020).

Foi criada também em 1990 a Associação Brasileira de Psicopedagogia -Seção Paraná, com sede em Londrina. E, em 1991, o grupo de estudos de Psicopedagogia de Curitiba transformou-se em uma Subseção da Seção Paraná (BARBOSA, 1994).

Outro evento importante ocorreu em 1992: a ABPp promoveu o II Congresso Brasileiro de Psicopedagogia e V Encontro de Psicopedagogos, abrangendo a temática "A Práxis Psicopedagógica na Realidade Nacional Brasileira". Durante a assembleia geral realizada nesse evento constituíram-se os princípios e orientações geradores do primeiro Código de Ética da Psicopedagogia, o qual tinha por primazia delimitar os objetivos da Psicopedagogia e as principais nuances da identidade do psicopedagogo.

Com a finalidade de discutir o trabalho psicopedagógico institucional, foi realizado, em 1994, o VI Encontro, com a Temática “A Psicopedagogia Institucional”. Em seguida, no mesmo ano, ocorreu a implantação de um Curso de Psicopedagogia pela ABPp, em caráter experimental, tomando como base um modelo de formação próprio, o qual foi fundamentado teoricamente seguindo a proposta do documento sobre a identidade profissional do Psicopedagogo elaborado em 1989 (SCOZ, 1998).

Em 1996, foi criada a Associação Brasileira de Psicopedagogia - Seção Bahia (ABPpBA), a qual prima pelo desenvolvimento de grupos de estudos, palestras, cursos, oficinas e 
atendimentos, objetivando contribuir para a formação e desenvolvimento do psicopedagogo com foco em uma perspectiva educacional inclusiva e transformadora (ABPp-BA, 2019).

Evidencia-se que, no ano de 1996, uma das pesquisadoras e fundadoras da Associação Brasileira de Psicopedagogia (ABPp), Neide de Aquino Noffs, defendeu a tese de doutorado na Universidade de São Paulo (USP), intitulada "Psicopedagogo na rede de ensino: a trajetória institucional de seus atores-autores", a qual foi a primeira tese no Brasil na área da Psicopedagogia (NOFFS, 2003). É importante destacar que a referida autora defende a importância do psicopedagogo como um novo profissional da educação. Ela foi presidente da ABPp nas gestões de 1995/1996 e 1997/1998, e coordena desde 1995 a comissão que busca a regulamentação da profissão de psicopedagogo em território brasileiro.

No ano de 1998, ocorreu em São Paulo o VIII Encontro de Psicopedagogos; no evento foram realizadas reflexões e discussões que resultaram na criação do primeiro cadastro de cursos de Psicopedagogia no Brasil. Também, a pesquisadora Maria Cecilia Almeida e Silva, no mesmo ano, teve a iniciativa de buscar uma fundamentação teórica para a Psicopedagogia, a qual "surgiu a partir da constatação de que a Psicopedagogia no Brasil se encontra aparentemente numa fase de pré-saber com características positivas deste estado [...]" (ALMEIDA E SILVA, 2018, p. 17).

No ano de 2003 foi criado o Projeto Lumiar de Atendimento Psicopedagógico da Associação Brasileira de Psicopedagogia da Seção Ceará, que buscou contribuir para o atendimento de pessoas que não apresentavam condições financeiras para custear a intervenção psicopedagógica (SILVA; CASTRO, 2007).

Nesse mesmo ano, segundo Barbosa (2007), ocorreu o I Encontro Paranaense de Psicopedagogia em Maringá e, em São Paulo, realizaram-se o VI Congresso Brasileiro de Psicopedagogia, o II Congresso Latino-Americano e o $\mathrm{X}$ Encontro Brasileiro de Psicopedagogos, nos quais foram realizados debates e discussões sobre a qualidade de formação dos profissionais psicopedagogos, tendo também como objetivo atualizar os cadastros de cursos de Psicopedagogia no Brasil.

No ano de 2005 foi reconhecido o primeiro curso de graduação em Psicopedagogia oferecido pela Pontifícia Universidade Católica do Rio Grande do Sul (PUCRS). Nesse período, dois outros cursos de graduação também estavam em andamento: um no Centro Universitário La Salle, localizado em Canoas, no Rio Grande do Sul, e outro no Centro Universitário FIEO, localizado em Osasco, no estado de São Paulo.

No Centro Universitário FIEO, que é a Fundação Instituto de Ensino para Osasco, foi criado um curso de especialização em Psicopedagogia em 1994 como experiência-piloto para 
um futuro curso de mestrado na área. No ano de 2006, no respectivo Centro Universitário, foi autorizada a criação do curso de mestrado, primeiramente com área de concentração em Psicopedagogia, sendo posteriormente reformulado para o curso de mestrado em Psicologia Educacional (UNIFIEO, 2020).

Ao longo da trajetória histórica da Psicopedagogia no Brasil, além da ABPp a nível nacional, foram criados Seções e Núcleos distribuídos em todo o território brasileiro. Atualmente a ABPp possui 15 Seções e 5 Núcleos distribuídos pelo território nacional. Confira-se na sequência: na Região Sul tem-se a Seção Rio Grande do Sul, Seção Santa Catarina, Seção Paraná, Núcleo Paraná Norte; na Região Sudeste tem-se a Seção São Paulo, Seção Rio de Janeiro, Núcleo Espírito Santo, Seção Minas Gerais e Núcleo Sul Mineiro; na Região Centro-Oeste, Seção Distrito Federal, Seção Goiás; na Região Nordeste, a Seção Bahia, Seção Sergipe, Seção Pernambuco, Núcleo Paraíba, Seção Rio Grande do Norte, Seção Ceará e Seção Piauí; e na Região Norte, tem-se a Seção Pará e o Núcleo Maranhão (ABPp, 2020).

Ressalta-se que o órgão representativo da Psicopedagogia no Brasil, a ABPp, desde a sua fundação prima por desenvolver ações e "promove cursos e eventos em que a tônica continua sendo o estudo sobre a identidade, as áreas de conhecimento, a formação do psicopedagogo, o reconhecimento da profissão" (NOFFS, 2003, p. 60).

Foi publicada a Resolução $n^{0}$ 1, de 6 de abril de 2018 (CNE, 2018), a qual estabelece diretrizes e normas para a oferta dos cursos de pós-graduação lato sensu denominados cursos de especialização, no âmbito do Sistema Federal de Educação Superior, conforme prevê o art. 39, parágrafo $3^{\circ}$, da Lei $n^{\circ} 9.394 / 1996$, e oferece também outras providências (BRASIL, 1996).

Após a publicação da Resolução supracitada, conforme a ABPp (2019b), a Comissão de Formação e Regulamentação apresentou ao Conselho Nacional da ABPp os referenciais de seu estudo, e a comissão compreende que deve sugerir uma Política de Formação que aponte os princípios que organizam as ações na área.

No IV Simpósio Nacional de Psicopedagogia, que ocorreu em 2019 em São Paulo, a temática foi "Psicopedagogia e Profissionalização: contextos e transformações". Tal Simpósio objetivou oportunizar a realização de diálogos, reflexões e proposições coletivas entre os pares que ofereciam subsídios aos profissionais psicopedagogos perante os desafios encontrados no fazer cotidiano no campo da Psicopedagogia.

$\mathrm{Na}$ cidade de Londrina, no estado do Paraná, ocorreu nos dias 4 e 5 de outubro de 2019 o I Simpósio de Psicopedagogia da Região Sul, que teve como tema "Diálogos com 
áreas afins - História, pesquisa e âmbitos de atuação". Além deste, aconteceram no Brasil, em 2019, o Simpósio de Psicopedagogia da Região Nordeste, da Região Norte, da Região Sudeste, e o Simpósio da Região Centro-Oeste, que foi realizado separadamente, um no Distrito Federal e outro em Goiás.

Portanto, a História da Psicopedagogia no Brasil é marcada pela criação de órgãos representativos, por lutas, movimentos e conquistas que fortaleceram essa área.

\section{Regulamentação e normatização da Psicopedagogia no Brasil}

O crescimento no número de profissionais atuando na área da Psicopedagogia motivou a criação de documentos com a finalidade de normatizar e nortear a atuação do psicopedagogo no Brasil. Reuniram-se em vários encontros psicopedagogos representantes de vários estados brasileiros, coordenadores de cursos de Psicopedagogia, representantes de Seções e Núcleos, os quais, com a colaboração da psicopedagoga argentina Sara Paín, buscaram discutir aspectos sobre o perfil profissional do psicopedagogo.

Destaca-se também que as discussões promovidas nos eventos de Psicopedagogia, a crescente expansão dos cursos de especialização na área nas cinco regiões brasileiras e a ampliação do número de profissionais formados direcionaram a ABPp a criar um documento a respeito da Identidade Profissional do Psicopedagogo. Com a necessidade de regulamentar a profissão do psicopedagogo, em 1988, os representantes da ABPp receberam orientação a partir do documento referente ao perfil profissional do psicopedagogo elaborado pela Prof ${ }^{\mathrm{a}}$ Guiomar Namo de Mello, a qual na época era deputada estadual (SCOZ, 1998).

Assim, os diversos eventos, debates e discussões contribuíram para a criação da primeira versão do Código de Ética do Psicopedagogo, que foi elaborado pelo Conselho Nacional da ABPp do biênio 91/92 e, posteriormente, reformulado pelo Conselho Nacional de Psicopedagogia no biênio 95/96.

É importante destacar que o Código de Ética do Psicopedagogo é um documento que é constantemente atualizado, regulamenta os princípios da Psicopedagogia, o exercício das atividades psicopedagógicas, a formação, as responsabilidades e deveres dos psicopedagogos e as relações com outras profissões. Estabelece as regras do sigilo profissional, retrata as normas para as publicações científicas, orienta como deve ser a publicidade profissional, trata dos honorários e traz observâncias referentes ao cumprimento do documento, que é recomendado pelos Conselhos Nacional e Estadual da ABPp. 
Em 1996, por meio do Deputado Federal Barbosa Neto, os membros da ABPp, compostos pela presidente, na época Neide de Aquino Noffs, pela vice-presidente, Nívea Fabricio, a presidente da Seção Goiás, Marilene de Azevedo Ribeiro, a vice-presidente da mesma Seção, Maristela Nunes Pinheiro, e o próprio Deputado Barbosa Neto participaram de uma audiência em Brasília, com o objetivo de esclarecer e explicar sobre a ABPp, articulando com os objetivos do III Congresso de Psicopedagogia, que ocorreria no mesmo ano, em 1996, o qual teve como objetivo discutir o campo de atuação do psicopedagogo e o perfil profissional.

Em 1997, o Deputado Barbosa Neto criou o primeiro Projeto de Lei $n^{\circ} 3.124 / 97$, que dispõe sobre a regulamentação da profissão de psicopedagogo; cria também o Conselho Federal e os Conselhos Regionais de Psicopedagogia e determina outras providências (BRASIL. CONGRESSO NACIONAL. CÂMARA DOS DEPUTADOS, 1997). O referido Projeto de Lei "visa disciplinar o exercício da Psicopedagogia como profissão, bem como as diversas áreas de atuação da mesma" (RUBINSTEIN; CASTANHO; NOFFS, 2004, p. 235).

Outro marco importante no campo da Psicopedagogia ocorreu em 2000, a criação das Diretrizes Básicas da Formação de Psicopedagogos no Brasil e os eixos temáticos para os Cursos de Formação em Psicopedagogia, os quais foram resultado dos eventos intitulados Pré-Congresso de Coordenadores de Curso e Supervisores de Estágio, V Congresso Brasileiro de Psicopedagogia, I Congresso Latino-Americano de Psicopedagogia e IX Encontro de Psicopedagogos (BARBOSA, 2007).

Em seguida, a ocupação de psicopedagogo no mercado de trabalho passou a ser reconhecida oficialmente em 2002, instituída na Classificação Brasileira de Ocupações (CBO), sendo inseridos na família ocupacional 2394-25 dos programadores, avaliadores e orientadores de ensino (ABPp, 2002). A partir da criação da CBO, espera-se, em termos de legislação nacional, que a profissão de psicopedagogo seja regulamentada mediante trâmites legais.

Com a expansão dos cursos em Psicopedagogia no Brasil, a Comissão de Formação e Regulamentação do Conselho Nacional da ABPp, sob a coordenação de Evelise Maria Labatut Portilho (PR), Luciana Barros de Almeida (GO) e Neide de Aquino Noffs (SP), juntamente com a equipe representativa da ABPp, criou, em 2008, o documento denominado Diretrizes Básicas de Formação do Psicopedagogo, que norteia a organização dos cursos em Psicopedagogia, os quais devem formar profissionais que garantam a aprendizagem como direito de todos os seres humanos. Em relação aos cursos lato sensu, observando-se a especificidade e complexidade da formação do psicopedagogo, os documentos da 
Psicopedagogia, na época, recomendavam que a carga horária mínima da especialização fosse de 600 horas presenciais, abrangendo estudo teórico e atividades práticas com estágios na área da Psicopedagogia.

Também no mesmo ano foi criado o Projeto de Lei no 3.512-C, de 2008, de autoria de Raquel Teixeira, que "dispõe sobre a regulamentação do exercício da atividade de Psicopedagogia", sendo livre em todo Brasil o exercício da atividade psicopedagógica, desde que observadas e respeitadas as disposições legais. Ressalta-se que, em 2010, o referido Projeto foi aprovado por unanimidade pela Comissão de Constituição e Justiça e Cidadania, mediante reunião deliberativa ordinária (BRASIL, 2008).

O Projeto de Lei 31/2010, o segundo de autoria da Deputada Federal Raquel Teixeira, que regulamenta a atividade de Psicopedagogia, também foi aprovado pela Comissão de Assuntos Sociais (CAS) do Senado Federal e, em seguida, retornou para a Câmara. Até 2019, o Projeto permaneceu em trâmite para votação no Congresso Nacional, e as etapas para regulamentação e votação foram acompanhadas pelos representantes da ABPp (BRASIL, 2010).

No Pré-Congresso do IV Simpósio Nacional de Psicopedagogia aconteceu a reunião com coordenadores de cursos que objetivou a atualização das Diretrizes da Formação de Psicopedagogos no Brasil (2018/2019). Nessa reunião, segundo a ABPp (2019b), foi apresentado um conjunto de indicadores, orientações para a construção das matrizes curriculares dos cursos de formação em Psicopedagogia nos níveis de graduação ou pósgraduação, sendo descritos a seguir na íntegra: 1) Flexibilização curricular - matriz curricular com conhecimentos específicos prevendo também conhecimentos necessários ao contexto regional; 2) Interdisciplinaridade/multidisciplinar/transdisciplinaridade; 3) Intervenção psicopedagógica - atuação supervisionada por psicopedagogo; 4) Pesquisa - intervenção e construção de conhecimento; 5) Gestão compartilhada (colegiado de curso) colaborativa, ambiente acolhedor (visão sistêmica); 5) Educação a Distância (EaD) - modelo híbrido cuidando da formação pessoal; 6) Carga horária mínima de 450 horas para o curso lato sensu e para o curso de graduação mínimo de 3.200 horas;

Com relação à distribuição da carga horária nos cursos lato sensu, a ABPp (2019b) sugere que, no mínimo, 360 horas dos cursos abordem conhecimentos específicos referências teórico-práticas dentro da área de conhecimento e 90 horas, no mínimo, sejam atividades de intervenção. É importante destacar que, conforme a ABPp (2019c), a carga horária de cursos de especialização com $360 \mathrm{~h}$ puramente se mostra insuficiente para a 
formação, destacando a necessidade da supervisão em Psicopedagogia para a formação e aperfeiçoamento profissional.

No ano de 2019 foi também realizada a última atualização do documento denominado Código de Ética do psicopedagogo pela Comissão de Ética e com anuência do Conselho Nacional da ABPp no triênio 2017/2019, sendo aprovado na Assembleia Geral realizada no dia 26 de outubro de 2019, que ocorreu no IV Simpósio Nacional de Psicopedagogia (ABPp, 2019a). Constata-se que desde a criação o referido documento foi reformulado quatro vezes e, conforme a ABPp (2019a, p. 1), é necessária a atualização constante do texto para que "se mantenha em conformidade com as expectativas da categoria profissional e da sociedade".

Ao detalhar os aspectos históricos da trajetória da Psicopedagogia, observa-se que muitos avanços ocorreram, os quais contribuíram para a abertura de novos espaços de atuação profissional, elaboração de leis, códigos e diretrizes especificando as atribuições e responsabilidades dos profissionais formados e ou especializados na área da Psicopedagogia, além de colaborar no fortalecimento de lutas em busca da regulamentação da profissão de psicopedagogo.

\section{Considerações finais}

Conclui-se que ao trazer os dados da trajetória histórica da Psicopedagogia no Brasil percebe-se a importância da $\mathrm{ABPp}$, dos congressos, eventos, debates e encontros realizados a nível regional, estadual e nacional, os quais contribuíram para discussões e reflexões sobre a Psicopedagogia no Brasil, a formação e atuação do psicopedagogo, a identidade profíssional e a regulamentação da profissão.

Salienta-se que os eventos também colaboraram para reflexões, discussões e elaboração de documentos, como o Código de Ética do Psicopedagogo, Diretrizes de Formação dos Psicopedagogos no Brasil, Parâmetros Nacionais para Elaboração de Concursos Públicos, entre outros.

Outrossim, a realização da tese fez perceber que a pesquisa teórico-bibliográfica aliada aos dados obtidos e analisados vêm oferecer subsídios capazes de fortalecer as ações e lutas em prol da regulamentação do cargo de psicopedagogo. A pesquisa dispõe de contribuições significativas no sentido de atribuir maior destaque ao profissional psicopedagogo e às suas contribuições em direção à aprendizagem e melhoria da educação para todos os educandos.

Essas percepções podem ser aprofundadas a partir da leitura completa da pesquisa; deixamos aqui essa sugestão. Espera-se que este estudo provoque inquietações acerca da 
Psicopedagogia no Brasil, mobilizando interessados a produzirem novos estudos que possam contribuir para o contínuo desenvolvimento da área no país.

\section{REFERÊNCIAS}

ABPp. Associação Brasileira de Psicopedagogia. CBO - Classificação Brasileira de Ocupações. 2002. Disponível em:

https://www.abpp.com.br/documentos_referencias_cbo_classificacao_brasileira_de_ocupacoe s.html. Acesso em: 23 outubro 2019.

ABPp. Associação Brasileira de Psicopedagogia. Diretrizes da formação de psicopedagogos no Brasil. 2013a. Disponível em:

https://www.abpp.com.br/documentos_referencias_diretrizes_formacao.html. Acesso em: 24 out. 2019

ABPp. Associação Brasileira de Psicopedagogia. Estatuto Social. 2013b. Disponível em: https://www.abpp.com.br/estatuto_nacional_registrado.pdf. Acesso em: 24 out. 2019.

ABPp. Associação Brasileira de Psicopedagogia. Código de Ética do Psicopedagogo. 2019a. Disponível em: https://www.abpp.com.br/documentos_referencias_codigo_etica.html. Acesso em: 27 out. 2019.

ABPp. Associação Brasileira de Psicopedagogia. Diretrizes da formação de psicopedagogos no Brasil. 2019b. Disponível em:

https://www.abpp.com.br/documentos_referencias_diretrizes_formacao.html Acesso em: 25 dez. 2019.

ABPp. Associação Brasileira de Psicopedagogia. Reunião com coordenadores: formação dos profissionais em Psicopedagogia. 2019c.

ABPp. Associação Brasileira de Psicopedagogia. ABPp no Brasil. 2020. Disponível em: https://www.abpp.com.br/abpp_no_brasil_pa.html. Acesso em: 20 jan. 2020.

ABPp-BA. Associação Brasileira de Psicopedagogia. Quem somos. Seção Bahia. 2019. Disponível em: https://abppbahia.com.br/quem-somos/abpp-secaobahia. Acesso em: 29 dez. 2019.

ABPp-GO. Associação Brasileira de Psicopedagogia. Histórico da Associação Brasileira de Psicopedagogia. Seção Goiás. 2020. Disponível em:

http://abppgo.com.br/index.php/historia/. Acesso em: 03 jan. 2020.

ALMEIDA E SILVA, M. C. Psicopedagogia: a busca de uma fundamentação teórica. São Paulo: Paz e Terra, 2018.

BAPTISTA, M. A contribuição das publicações boletim e revista psicopedagogia para a construção da identidade da psicopedagogia. Revista Psicopedagogia, São Paulo, v. 15, n. 38, p. 17-28, 1996. 
BARBOSA, L. M. S. A epistemologia da psicopedagogia: reconhecendo seu fundamento, seu valor social e seu campo de ação. Comemorando os 15 anos da ABPp - Paraná Sul, 2006.

Revista Psicopedagogia, São Paulo, v. 24, n. 73, p. 90-100, 2007.

BARBOSA, L. M. S. A psicopedagogia e o momento do aprender. São José dos Campos: Pulso, 2006.

BARBOSA, L. M. S. Comprovação de prática para fins de credenciamento como sócio titular da Associação Brasileira de Psicopedagogia. Curitiba, 1994.

BARBOSA, L. M. S. Intervenção psicopedagógica no espaço da clínica. Curitiba: InterSaberes, 2012.

BERLIM, C. G.; PORTELLA, F. O. Psicopedagogia e escola: um vínculo natural. In: BOMBONATTO, Q.; MALUF, M. I. (org.). História da psicopedagogia e da ABPp no Brasil: fatos protagonistas e conquistas. Rio de Janeiro: Wak, 2007. p. 85-89.

BLASZKO, C. E. O psicopedagogo na rede pública municipal em sete estados brasileiros: cenários e desafios. 2020. 162 f. Tese (Doutorado em Educação) - Pontifícia Universidade Católica do Paraná, Curitiba, 2020.

BRASIL. Lei n. 9.394, de 20 de dezembro de 1996. Estabelece as diretrizes e bases da Educação Nacional. Brasília, DF, 1996. Disponível em: http://www.planalto.gov.br/ccivil_03/ Leis/L9394.htm. Acesso em: 09 mar. 2018.

BRASIL. Congresso Nacional. Câmara dos Deputados. Projeto de Lei n. 3.124, de 1997. Dispõe sobre a regulamentação da profissão de Psicopedagogo, cria o Conselho Federal e os Conselhos Regionais de Psicopedagogia e determina outras providências. Brasília, 1997. Disponível em: https://www.abpp.com.br/pl3124-1997.pdf. Acesso em: 13 jul. 2017.

BRASIL. Congresso Nacional. Senado Federal. PL 3512-C/2008. Dispõe sobre a regulamentação do exercício da atividade de Psicopedagogia. Brasília, 2008. Disponível em: https://www.camara.leg.br/propostas-legislativas/398499. Acesso em: 11 jul. 2018.

BRASIL. Congresso Nacional. Senado Federal. Projeto de Lei da Câmara n. 31, de 2010. Dispõe sobre a regulamentação do exercício da atividade de Psicopedagogia. Brasília, 2010. Disponível em: https://www25.senado.leg.br/web/atividade/materias/-/materia/96399. Acesso em: 10 jul. 2018.

CNE. Conselho Nacional de Educação. Resolução n. 1, de 6 de abril de 2018. Estabelece diretrizes e normas para a oferta dos cursos de pós-graduação lato sensu denominados cursos de especialização, no âmbito do Sistema Federal de Educação Superior, conforme prevê o Art. 39, § $3^{\circ}$, da Lei no 9.394/1996, e dá outras providências. Brasília, 2018. Disponível em: http://portal.mec.gov.br/docman/abril-2018- pdf/85591-rces001-18/file. Acesso em: 05 jan. 2020.

GIL, A. C. Como elaborar projetos de pesquisa. São Paulo: Atlas, 2002.

NOFFS, N. A. Psicopedagogia na rede de ensino: a trajetória institucional de atores-autores. São Paulo: Elevação, 2003. 
PORTILHO, E. M. L. Formação do psicopedagogo na instituição. Revista Psicopedagogia, São Paulo, v. 11, n. 24, p. 25-27, 1992.

RODRIGUES, A. L. F. P.; NOFFS, N. A.; FABRÍCIO, N. M. C. Regulamentação da profissão. Revista Psicopedagogia, São Paulo, v. 16, n. 42, p. 5-7, 1997.

RUBINSTEIN, E.; CASTANHO, M. I.; NOFFS, N. A. Rumos da psicopedagogia brasileira. Revista Psicopedagogia, São Paulo, v. 21, n. 66, p. 225-238, 2004.

SCOZ, B. Psicopedagogia e realidade escolar: o problema escolar e de aprendizagem. Petrópolis: Vozes, 1998.

SILVA, G. M. F.; CASTRO, M. J. W. M. Imersão do Projeto Lumiar: um mergulho dentro de nós mesmos. Revista Psicopedagogia, São Paulo, v. 24, n. 73, p. 45-49, 2007.

TEIXEIRA, M. L. G.; FREITAS, S. B. O trabalho do NOAP junto aos profissionais que atuam na escola. Revista Psicopedagogia, São Paulo, v. 12, n. 25, p. 20-23, 1993.

UNIFIEO. Sobre a UNIFIEO. 2020. Disponível em: http://www.unifieo.br/index.php/201507-06-20-28-50/sobre-o-unifieo. Acesso em: 10 jan. 2020.

ZENICOLA, A. M.; CASTRO, C. S. F. A história da psicopedagogia no Rio de Janeiro. In: MALUF, M. I.; BOMBONATTO, Q. História da psicopedagogia e da ABPp no Brasil. Rio de Janeiro: Wak, 2007. p. 149-153.

\section{Como referenciar este artigo}

BLASZKO, C. E.; PORTILHO, E. M. L. Retrospectiva histórica da psicopedagogia no contexto brasileiro: gênese, documentação e legalização. Revista Ibero-Americana de Estudos em Educação, Araraquara, v. 16, n. 3, p. 2117-2132, jul./set. 2021. e-ISSN: 19825587. DOI: https://doi.org/10.21723/riaee.v16i3.15415

Submetido em: 10/12/2020

Revisões requeridas em: 05/01/2021

Aprovado em: 10/02/2021

Publicado em: 01/07/2021 